\title{
Studies toward the synthesis of the L-thyroxine hormone.
}

\author{
Rafael D. C. Gallo, Carlise Frota and Cristiano Raminelli ${ }^{\star}$ \\ Faculdade de Ciências Exatas e Tecnologia, Universidade Federal da Grande Dourados, \\ Rodovia Dourados-Itahum, Km 12, Cidade Universitária, Dourados, MS, CEP 79.804-970, Brazil \\ *e-mail address: raminelli@ufgd.edu.br
}

Keywords: total synthesis, L-thyroxine, T4 hormone

\section{INTRODUCTION}

L-Thyroxine (T4) (1) is a hormone produced by the thyroid gland. The thyroid gland uses iodine, from exogenous sources, to produce L-thyroxine (1), which acts as a precursor of 3,5,3'-triiodothyronine (T3). Individuals with low levels of T4 and T3 can suffer from hypothyroidism. Accordingly, L-thyroxine (1) has been indicated for the treatment of this type of endocrine disorder. Although since 1927 the production of the T4 hormone is carried out in laboratory, ${ }^{1}$ short synthetic routes involving mild reaction conditions to obtain this important substance are still of considerable interest. In this work we show our preliminary results toward the synthesis of L-thyroxine (1) employing a route that will use in two steps an efficient and selective diiodination reaction developed in our research group. $^{2}$

\section{RESULTS AND DISCUSSION}

Initially, we present the retrosynthetic analysis for L-thyroxine (1) (Scheme 1).

Scheme 1. Retrosynthetic analysis for L-thyroxine (1).<smiles>Cc1cc(CC(N)C(=O)O)cc(I)c1Oc1cc(I)c(O)c(I)c1</smiles><smiles>COC(=O)NC(Cc1cc(I)c(Oc2ccc(OC)cc2)c(I)c1)C(=O)OCc1ccccc1</smiles><smiles>CC(=O)OC(Cc1cc(I)c(O)c(I)c1)NC(=O)C(C)=O</smiles>

Reaction of the amino acid L-tyrosine (5) with thionyl chloride in methanol led to the formation of the L-tyrosine methyl ester (6) in quantitative yield. Next, the ester $\mathbf{6}$ had its amino group selectively protected with di-tert-butyl dicarbonate resulting in the $\mathrm{N}$-BocL-tyrosine methyl ester (7) in an isolated yield of $98 \%$. Afterwards, compound 7 was subjected to the diiodination reaction, which uses iodine and hydrogen peroxide $(30 \%)$ in water at room temperature for 24 hours, producing the diiodinated intermediate $\mathbf{3}$ in a good yield of $80 \%$ (Scheme 2).

Scheme 2. Sequence of reactions toward the synthesis of L-thyroxine (1).

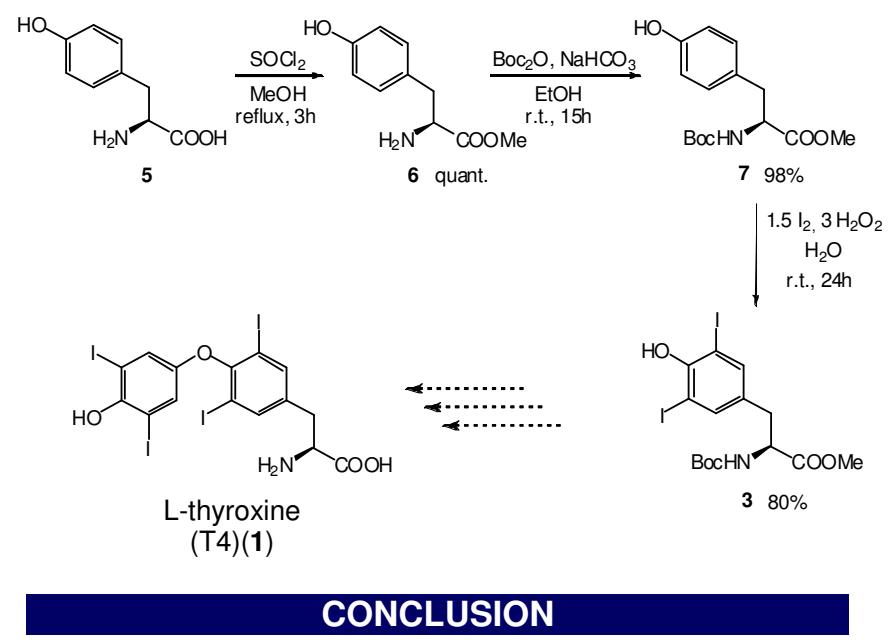

In this work we present the synthesis of the diiodinated intermediate $\mathbf{3}$, obtained by an efficient and selective diiodination reaction developed in our research group, which will be employed in the production of L-thyroxine (T4) (1).

\section{ACKNOWLEDGEMENTS}

We acknowledge CNPq and FUNDECT for financial support.

\section{REFERENCES}

${ }^{1}$ Harington, C. R.; Barger, G. Biochem. J. 1927, 21, 169-183.

${ }^{2}$ Gallo, R. D. C.; Gebara, K. S.; Muzzi, R. M.; Raminelli, C. J. Braz. Chem. Soc. 2010, 21, 770-774. 